\title{
Principles of selection and optimization of cooling systems in public buildings
}

\author{
Alexey Busakhin ${ }^{1, *}$ \\ ${ }^{1}$ Moscow State University of Civil Engineering, 129337, Yaroslavskoe ch., 26, Moscow, Russia
}

\begin{abstract}
Aspects of selecting the most effective refrigerating machine for air conditioning systems, taking into account the comparative analysis of the energy efficiency of the refrigerating machine are considered. The purpose of the work is to improve the regulatory framework governing the design, construction and operation of buildings and structures, to obtain sufficient theoretical and reliable calculated data to determine the standardized parameters and clarify the requirements for the design, construction and operation of buildings and structures. The requirements should be focused on ensuring safe for human health conditions of residence and stay in buildings and structures and the energy efficiency of buildings and structures in order to implement the requirements of the Federal Law of December 30, 2009 No. 384-FZ "Technical Regulations on the Safety of Buildings and Structures". The aim of the study is to ensure the protection of the life and health of citizens, property of individuals and legal entities, state or municipal property, to bring methods for determining operational characteristics and assessment methods to the uniformity, to ensure mutual consistency of existing regulatory technical documents in the construction industry. The object of the study is the refrigeration and air conditioning systems of public buildings.
\end{abstract}

\section{Introduction}

Refrigeration systems for ensuring the microclimate parameters of public buildings are large consumers of material and energy resources. The refrigeration capacity of the systems can reach several thousand kilowatts, and their cost is tens of millions of rubles.

Optimization of the refrigeration system allows one to achieve savings in the initial costs for their development, as well as to reduce energy consumption during operation by 15 $25 \%$.

In practice, various basic refrigeration schemes are used (direct cooling, multi-zone freon systems, cooling of the intermediate heat carrier, built-in and remote condensers with air and water cooling, an intermediate glycol circuit, open and dry cooling towers, irrigated coolers, free cooling, waste heat recovery, absorption refrigeration machines, combined systems, etc.) [1-5].

The choice of the optimal configuration scheme for equipment and operating modes of refrigeration stations is a difficult task that requires technical and economic calculations.

\footnotetext{
*Corresponding author: a7554253@yandex.ru
} 
When choosing a refrigeration system, there is often a conflict of interest between the participants in the construction.

The developer, private investor is interested in the minimum construction cost (initial cost). As a result, the cheapest equipment with the highest energy consumption is selected.

The equipment supplier is interested in promoting its equipment, so it is necessary to win the tender and secure the supply. The result is the choice of irrational circuit solutions, excessive or insufficient optional equipment.

The maintenance department is concerned with simplifying and reducing routine maintenance of the system, which leads to the choice of sub-optimal system configurations, overestimating the initial and annual costs [6-10].

The end consumer (customer: municipal authorities or a private company bearing the costs of maintaining the facility) is interested in the minimum costs of maintaining the system, the main share of which is the cost of energy resources (electricity and heat). Therefore, his subjective decision becomes the choice of the most expensive energy efficient equipment with an unacceptably long return on investment.

In the course of the work, a review and analysis of modern scientific and technical, normative, reference and methodological literature concerning a scientific and technical problem was carried out. Domestic and foreign studies related to the issues of increasing energy efficiency, reliability and safety of refrigeration systems for public buildings through the optimization of design solutions of refrigeration centers, the use of energy efficient, environmentally friendly equipment are analyzed. As a result of the analysis, the most promising, advanced technical solutions have been identified that allow increasing the energy efficiency and reliability of refrigeration systems.

The values of standardized indicators of energy efficiency of refrigeration equipment are given, methods of its improvement are considered, a calculation method is developed that allows a uniform assessment of the energy, economic and environmental efficiency of refrigeration systems. Methodological guidelines have been developed for choosing the optimal configuration, design solutions and equipment for refrigeration systems for public buildings, ensuring their reliable, safe and energy-saving operation.

The selected design solution of the refrigeration system must correspond to the design features and functional purpose of buildings according to the following indicators (consumer qualities):

- availability of engineering and utility services rooms with limited access for installation of the refrigeration center, hydronic module and auxiliary equipment;

- sufficient area and bearing capacity of floors, roofs, the presence of utility shafts;

- ensuring the permissible sound pressure in the surrounding buildings;

- interior design solutions;

- ease of use;

- possibility of upgrading the system.

\section{Materials and methods}

When choosing refrigeration systems for public buildings, the following factors must be considered:

1. Parameters of outdoor climate.

The specified parameters of the microclimate in the premises of public buildings should be ensured within the design parameters of the outside air for the corresponding construction areas, regulated by SP131.13330. According to SP 131.13330, the parameters of temperature and enthalpy for ventilation and air conditioning systems in the warm season are determined as parameters $\mathrm{B}$. 
In addition to the correct choice of design conditions for determining the maximum capacity of the equipment, it is also necessary to take into account the change in climatic parameters during the year or season.

2. Heat gain calculation.

The most important value that affects the required capacity of the refrigeration system is the flow of heat through the translucent outer fences of the building.

3. Requirements for reliability, safety and environmental friendliness of refrigeration systems

The design, installation and operation of refrigeration systems should be carried out taking into account the safety and environmental requirements, standardized by GOST EN 378-1, 378-2, 378-3, 378-4 [15,16,17].

4. Choice of safe refrigerants.

5. Environmental efficiency of refrigeration supply systems in terms of contribution to global warming.

Refrigerating machines and installations operating on non-toxic, environmentally friendly refrigerants with a low global warming potential (GWP) and zero ozone-depleting potential (ODP) should be used in refrigeration systems [GOST EN 378-1, Appendices B, $\mathrm{E}]$.

The ecological efficiency of refrigeration equipment is determined by its influence on the greenhouse effect.

Improving the energy efficiency of the system is a much more effective means of reducing the greenhouse effect than reducing the refrigerant charge.

6. Economic efficiency

To assess the economic efficiency of refrigeration systems, it is necessary to determine the following initial data:

the amount of investment $\mathrm{K}$ for each type of refrigeration system;

the estimated value of the annual intermediate income $\Delta \mathrm{D}$ for each type of refrigeration system;

the calculated value of the discount rate $\mathrm{r}$;

service life of refrigeration supply systems $\mathrm{T}$.

\section{Results: classification of cold supply systems for buildings}

The choice of the building cooling system is determined by the architectural and planning solutions and the purpose of the building. Figures 1 and 2 suggest the building cold supply system classification.

Ways to improve the energy efficiency of refrigeration systems:

1. Use of modern energy efficient equipment

2. Expansion and refinement of the economically justified field of application of absorption refrigerating machines and heat pump installations using the surface layers of the earth (soil and water bodies).

3. Improvement of the basic schemes of cold supply of buildings (redundancy levels, rejection of the intermediate glycol circuit, irrigated cooling towers, heat / cold recovery, etc.).

4. Optimization of equipment control algorithms (selection of control parameters, variable coolant flow rate, etc.).

5. Decrease in the installed capacity of the cold supply system due to the correct consideration of the seasonal dynamics of the outdoor climate change and the accumulating capacity of the building structures.

6. Use of advanced cold storage systems. 
7. Reducing the cold demand of central air conditioners by using indirect evaporative cooling and cold recovery systems in rotary absorption heat exchangers.

8 . Heat recovery of the chiller condenser.

9. Improving the efficiency of refrigeration equipment by eliminating the glycol circuit

10. Improving the efficiency of refrigeration equipment by using indirect evaporative cooling of supply air.

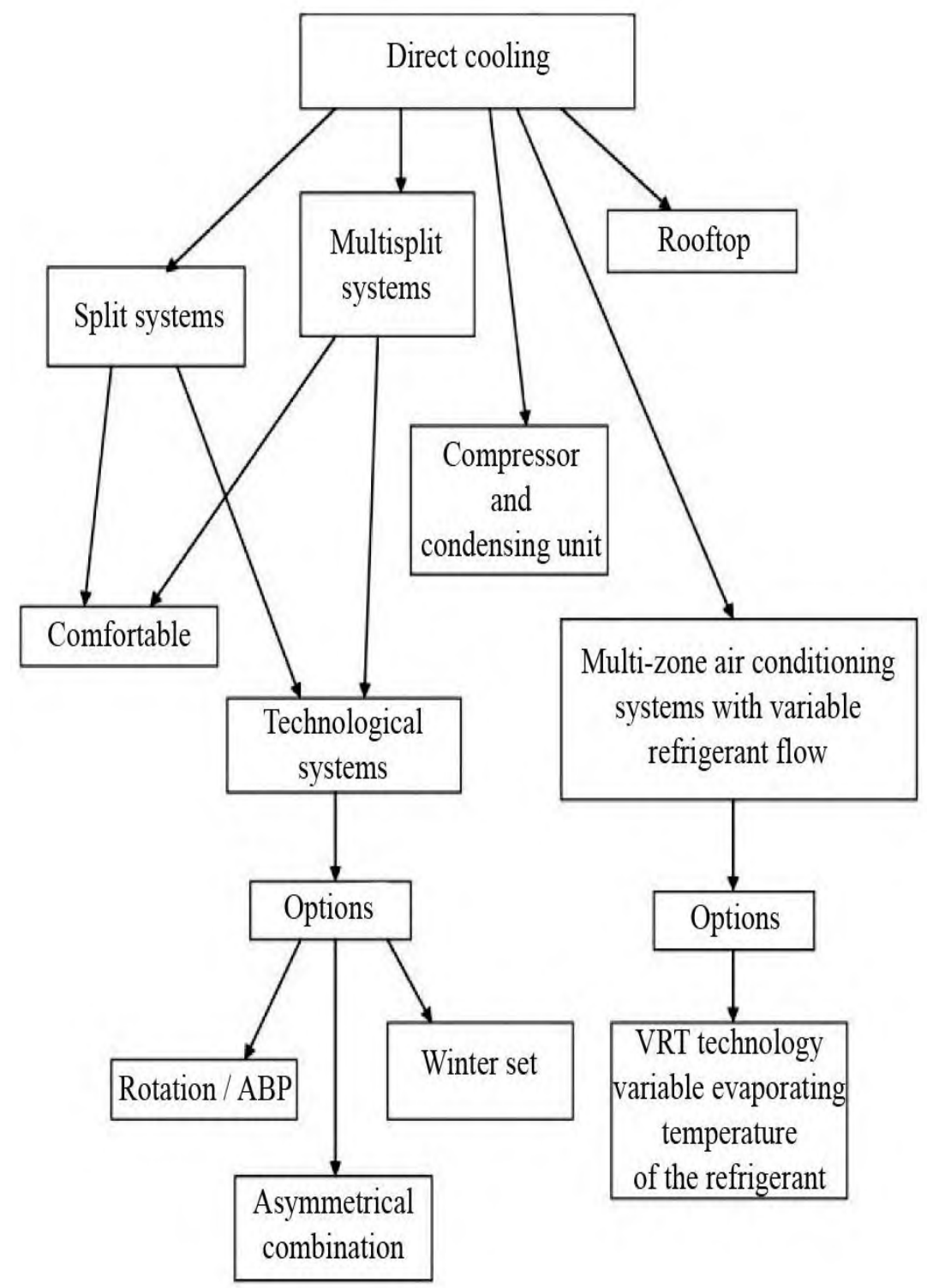

Fig. 1. Building cold supply system classification (cooling principles), $1^{\text {st }}$ part. 


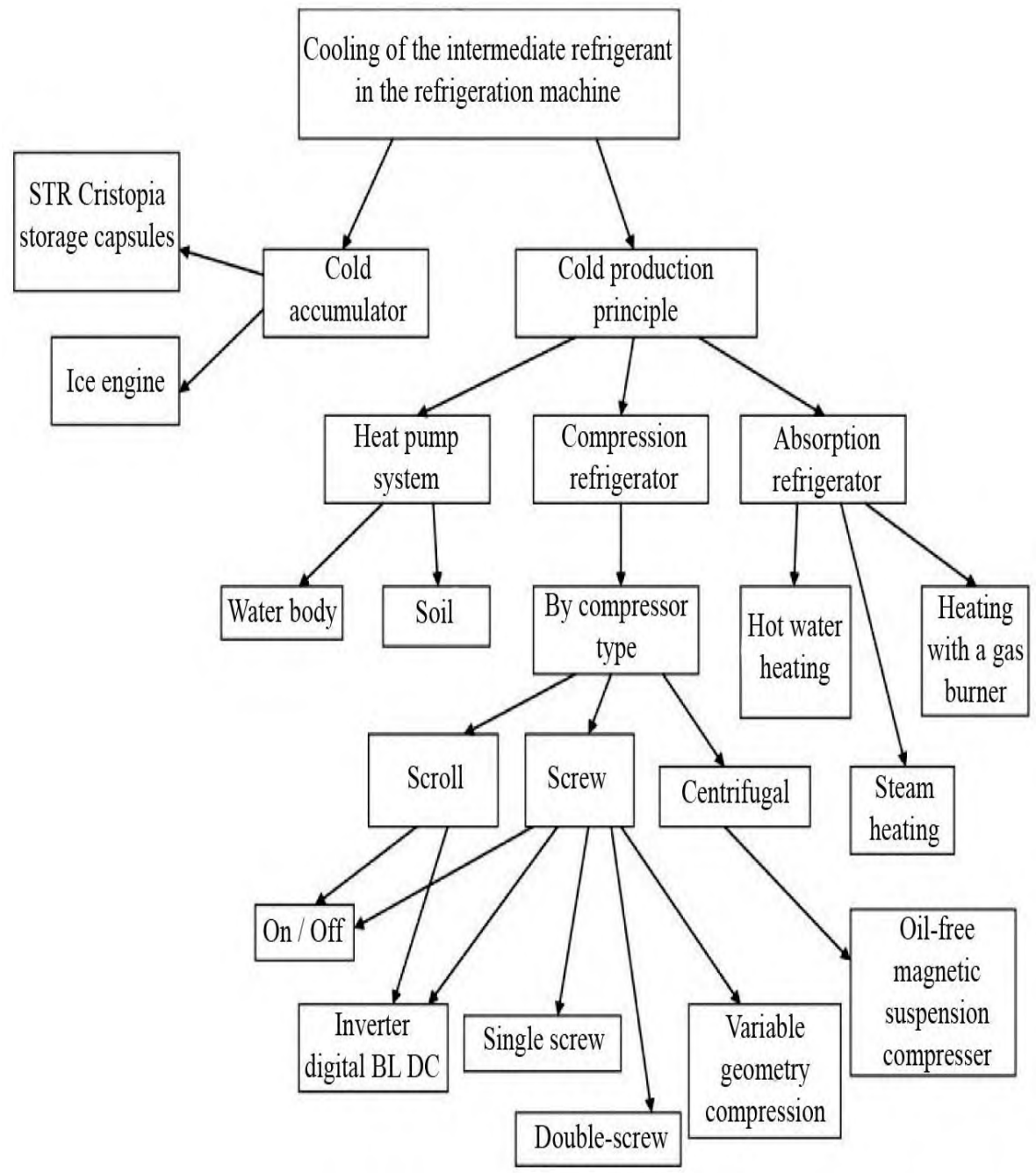

Fig. 2. Building cold supply system classification (cooling principles), $2^{\text {nd }}$ part.

Table 1. Energy efficiency class of chillers of various types in cooling mode.

\begin{tabular}{|c|c|c|c|}
\hline \multirow{2}{*}{$\begin{array}{c}\text { Energy } \\
\text { efficiency class }\end{array}$} & \multicolumn{3}{|c|}{ EER value by the type of condenser } \\
\cline { 2 - 4 } & air cooled & Water cooled & Remote \\
\hline A & $\geq 3.1$ & $\geq 5.05$ & $\geq 3.55$ \\
\hline B & $2.9 \div 3.1$ & $4.65 \div 5.05$ & $3.4 \div 3.55$ \\
\hline C & $2.7 \div 2.9$ & $4.25 \div 4.65$ & $3.25 \div 3.4$ \\
\hline D & $2.5 \div 2.7$ & $3.85 \div 4.25$ & $3.1 \div 3.25$ \\
\hline E & $2.3 \div 2.5$ & $3.45 \div 3.85$ & $2.95 \div 3.1$ \\
\hline F & $2.1 \div 2.3$ & $3.05 \div 3.45$ & $2.8 \div 2.95$ \\
\hline G & $<2.1$ & $<3.05$ & $<2.8$ \\
\hline
\end{tabular}


Table 2. Energy efficiency class of chillers of various types in heating mode.

\begin{tabular}{|c|c|c|}
\hline \multirow{2}{*}{$\begin{array}{c}\text { Energy } \\
\text { efficiency class }\end{array}$} & \multicolumn{2}{|c|}{ Value by the type of condenser } \\
\cline { 2 - 3 } & air cooled & Water cooled \\
\hline A & $\geq 3.2$ & $\geq 4.45$ \\
\hline B & $3.0 \div 3.2$ & $4.15 \div 4.45$ \\
\hline C & $2.8 \div 3.0$ & $3.85 \div 4.15$ \\
\hline D & $2.6 \div 2.8$ & $3.55 \div 3.85$ \\
\hline E & $2.4 \div 2.6$ & $3.25 \div 3.55$ \\
\hline F & $2.2 \div 2.4$ & $2.95 \div 3.25$ \\
\hline G & $<2.2$ & $<2.95$ \\
\hline
\end{tabular}

\section{References}

1. O. Ya. Kokorin, Modern air conditioning systems (Moscow, 2003)

2. A. A. Rymkevich, System analysis of optimization of general ventilation and air conditioning (Saint Petersburg, 2003)

3. V. K. Savin, Building Physics: Energy Transfer, Energy Efficiency, Energy Saving (Moscow, 2005)

4. STO NOSTROY 2.15.181-2015 "Internal engineering networks of buildings and structures. Refrigeration systems. Installation and commissioning works. Rules, control of implementation, requirements for work results" (Moscow, 2015)

5. STO NOSTROY 2.23.164-2014 "Internal engineering networks of buildings and structures. Refrigerating centers. Design and installation rules, control of implementation, requirements for work results" (Moscow, 2014)

6. M. G. Tarabanov, AVOK 6, 20-27 (2011)

7. Yu. M. Seliverstov, V. V. Efremov, AVOK 1, 30-33 (2013)

8. O. Ya. Kokorin, AVOK 1, 82-86 (2014)

9. I. V. Synkov, AVOK 3, 64-71 (2016)

10. A. N. Gavrilov, A. S. Strongin, AVOK North-West 4, 70-72 (2017)

11. SP 60.13330-2020 "Heating, Ventilation and Air Conditioning" (Moscow, 2020)

12. SP 131.13330.2012 Building climatology (Moscow, 2012)

13. E. I. Tertichnik, Ventilation (Moscow, 2015)

14. Application of mechanical ventilation systems in residential buildings. URL : https://www.abok.ru/for_spec/articles.php?nid=6267

15. V.A. Zhila, E.A. Gusarova, D.M. Gulukin, Scientific review 20, 38-44 (2017)

16. V.A. Zhila, E.B. Solovieva, D.M. Gulyukin, Scientific Review 22, 27-32 (2016) 